\title{
Community-based nursing education in South Africa: A grounded-middle range theory
}

\author{
Ntombifikile G. Mtshali ${ }^{* 1}$, Nomthandazo S. Gwele ${ }^{2}$ \\ ${ }^{1}$ School of Nursing, University of KwaZulu-Natal, Durban, South Africa \\ ${ }^{2}$ Faculty of Health Sciences, Durban University of Technology, Durban, South Africa
}

Received: February 25, 2015

Accepted: May 3, 2015

Online Published: November 2, 2015

DOI: $10.5430 /$ jnep.v6n2p55

URL: http://dx.doi.org/10.5430/jnep.v6n2p55

\begin{abstract}
Background: The change to a democratically elected government in South Africa in 1994 brought with it an impetus for change in public health and education systems, which was signalled by a number of policy documents. Traditional content-driven education was to be replaced by a community-oriented approach to education. Community-based education was to be the vehicle through which health care students and health personnel educators would be equipped with the comprehensive knowledge, competencies and attitudes needed to respond to the health care needs of the South African population. There was, however, no shared understanding of the meaning of the term, community-based education, in the country. The purpose of this study was (a) to conceptualise the phenomenon CBE within the South African context, and (b) to develop a middle-range theory that would guide the practice of $\mathrm{CBE}$ in basic nursing education in the country. This article focuses only on describing the middle range theory of CBE.

Methods: A grounded theory approach was used to guide the research process. Purposive sampling followed by theoretical sampling resulted in 41 participants comprising of heads of nursing schools, program directors, facilitators from six nursing education institutions and policy makers. Data was collected by means of observations, interviews and analysis of program documents. Observations were carried out in community and classroom settings. Data analysis was performed using open, axial and selective coding.

Results: The results showed that in South Africa, community based nursing education was viewed as (a) relevant education; (b) responsive education; (c) education for social justice; and (d) a conscious and deliberate primary health care socialization process. Importantly, a process-outcomes approach to education was seen as the most appropriate curriculum approach for community based nursing education.

Conclusions: The tentative theory from this study requires subjection to scholarly critique and validity testing in order to facilitate its evolvement towards becoming a higher level substantive theory.
\end{abstract}

Key Words: Community-based education, Nursing education, Curriculum, Grounded theory, Middle-range theory

\section{INTRODUCTION}

The World Health Organisation in 2008 made a call for the re-engineering of Primary Health Care (PHC) for universal access to health care. ${ }^{[1]}$ In line with this call access to health care is serving as a driving force in a number of health care systems. Access to health care is a constitutional right in South Africa and the PHC approach used by the Health Care System is a tool to promote this right. Most governments

\footnotetext{
*Correspondence: Ntombifikile G. Mtshali; Email: Mtshalin3@ukzn.ac.za; Address: School of Nursing, University of KwaZulu-Natal, Durban, South Africa.
}

Published by Sciedu Press 
and health professionals clearly recognize that health professionals' education must be adapted to a primary health care approach in order to be relevant to the health needs of the population. ${ }^{[2-4]}$ Moreover, it has been argued that the education of health professionals should be a shared responsibility of the community, service and training institutions ${ }^{[5]}$ to ensure production of health professionals with relevant skills that are appropriate to the health system context. ${ }^{[6,7]}$

\subsection{Background to the study}

With the change of government in South Africa, a plethora of policy documents called for reorientation of education in the health professions from the traditional content-based approach to a community-oriented approach. ${ }^{[8-10]}$ Essentially, community-based education (CBE) was to be the vehicle through which health care students and health personnel educators would be equipped with comprehensive knowledge, competencies and attitudes needed to respond to the health care needs of the South African population. ${ }^{[4]} \mathrm{CBE}$ is used globally to provide relevant PHC oriented learning experiences, where students learn to provide services to communities in remote and under-resourced settings. ${ }^{[11]}$

Nurse educators nowadays are challenged to embrace teaching and learning approaches which are in line with national health policies and health care system reforms. With the call for the re-engineering of PHC for universal health coverage, ${ }^{[1]}$ a number of countries have health policies which are PHC oriented. It is imperative for nursing education programs to be responsive to the national health policies ${ }^{[12,13]}$ as they have to prepare graduates who are able to function at all levels of the health care system. ${ }^{[14]}$ Part of preparing responsive nursing students includes the use of appropriate and diverse practical placement settings for experiential learning. ${ }^{[14,15]}$ Appropriate practice placement settings should include traditional settings, such as hospitals, as well as nontraditional practice settings, such as communities, patients' homes and hospital-linked outreach services.

Research shows that using communities for experiential learning has a number of positive outcomes, including facilitating the development of professional competencies in line with the demands of the health care system ${ }^{[12]}$ a better understanding of the social determinants of health and their impact on the health of the population ${ }^{[4]}$ increased understanding of social justice issues and their influence on health ${ }^{[13]}$ interprofessional and multi-disciplinary approaches to addressing health issues; and development of leadership behaviours in students. ${ }^{[12,15]}$ More importantly, students' exposure to learning in diverse community-based settings prepares them for life after graduation and stimulates in them a special interest and motivation to work with communities, including remote, rural and under-resourced health care settings because these settings resemble those in which they underwent educational preparation. ${ }^{[15-17]}$

CBE is a familiar concept in South Africa, with a number of nursing education institutions having community-based education programs. ${ }^{[4]}$ However, literature shows that although CBE is a familiar concept, there is a lack of shared common understanding of what this phenomenon entails. ${ }^{[18]}$ One of the reasons for this could be that CBE arose as a "reaction" to the realization of the inadequacy of traditional education programs in preparing graduates with relevant knowledge and skills to meet the health needs of the community. ${ }^{[16,17,19,20]}$ Another reason could be that CBE programs in South Africa were popularised by the sudden availability of external donor funds, particularly from the Kellogg Foundation as stated by Gwele in Mtshali ${ }^{[4]}$ which resulted in a number of unconnected and unrelated CBE programs being implemented from 1995-2000. This preceded and almost precluded any form of professional and/or intellectual discourse on what CBE entails. It is also acknowledged that in a country as heterogeneous as South Africa, especially with regard to cultures, ethnicity, religion and socio-economic factors, a certain amount of diversity is inevitable, both in the nature of health services and in CBE programs. While such diversity can be celebrated, it should not preclude a shared understanding of what constitutes CBE in the South African context.

\subsection{Research purpose and objectives}

The purpose of this study was to (a) conceptualise the phenomenon CBE within the South African context and (b) develop a middle-range theory that would guide the practice of CBE in basic nursing education in the country. However, the focus of this article will only be on describing the middle range theory of CBE. The objectives of this part of the study were to (a) determine the goals of a middle-range theory of CBE; (b) develop the assumptions that underpin CBE as conceptualised in this paper; (c) identify and define the substantive concepts of CBE; and (d) explain the linkages and/or relationships between the concepts and or categories that form the building blocks of the developed theory.

\subsection{Area description}

It was determined that only institutions with well-established community-based basic nursing education programs would be included in the study. Four university-based nursing schools with well-established CBE programs were identified and the South African Nursing Council (SANC) assisted in identifying two nursing colleges with CBE programs; both of which were included in the study. 


\section{MeTHODS}

\subsection{Research approach}

A grounded theory approach by Strauss and Corbin ${ }^{[21,22]}$ was used to guide the process of theory development. Grounded theory was deemed appropriate because very little had been done in terms of research aimed at understanding the phenomenon of CBE, either in South Africa or globally. In this particular study, Strauss and Corbin's grounded theory approach was used because some literature had to be reviewed in order to establish the need for the study of this nature and to refine the research question. Secondly, the researchers themselves were embedded in the practice of $\mathrm{CBE}$ and, as practitioners of education, could not truly claim any "a priori" knowledge of CBE before embarking on the study. Nevertheless, the limitations of Strauss and Corbin's approach as expressed in the reviewed literature were taken into consideration, especially the need to ensure that data analysis moves beyond conceptual descriptions of the phenomenon under study to conceptualisation and theorizing. ${ }^{[23]}$

\subsection{Sampling procedure and participants' description}

The initial group of participants was purposively selected and theoretical sampling was thereafter followed as guided by the initial participants. The sampling process was based on the participants' involvement in CBE. Theoretical sampling continued until data saturation was achieved, based on the completeness of all codes and when no new conceptual information was available to indicate new codes or expansion of existing codes. The sample size comprised 41 participants. Two (2) of the participants were CBE program directors, five were the heads of school in the institutions where there were no $\mathrm{CBE}$ program directors, 11 were level coordinators, 17 were facilitators and six were members of the SANC education committee.

\subsection{Data collection process}

Data was collected in two phases by means of observation, document analysis and interviews. The first phase was directed towards examining and analysing the practice of $\mathrm{CBE}$ in the selected nursing schools. During this phase, a minimum of five days was spent on each site mainly doing observations and analysing documents. The phenomenon of $\mathrm{CBE}$ was observed as it occurred in community learning settings and in classroom settings. Hand written notes and memos were utilized to provide backup information throughout the process of data collection. Clarification-focused interviews, based on the data that emerged during observations, were conducted on the last two days at each site with the intention of cross checking, filling of gaps, and verification of categories and concepts that emerged from the data.

Published by Sciedu Press
CBE program documents, including the schools' respective philosophy and mission statements, conceptual frameworks, the level or course outlines and evaluation instruments were analysed in relation to the data that emerged during observations and clarification interviews. This process of analysing documents illuminated each school's perspective and interpretation of CBE. Ongoing and concurrent analysis of data at this stage yielded preliminary concepts and constructs describing CBE as it was understood and practised at the selected institutions. These concepts and constructs formed the basis for the second phase data collection. While it is impossible to report all the results of an extensive study such as this in one article, Figure 1 contains an illustration to help the reader understand the foundation of the middle-range theory presented in this paper.

The second phase focused on interviews, which were informed by the data collected during observations. The intent was to bring forth the participants' understanding of and the meaning behind what was practiced as CBE. Interviewing participants was in line with Strauss and Corbin's ${ }^{[22]}$ emphasis on asking questions as a primary tool of collecting data in a grounded theory approach. Furthermore, according to Glaser, ${ }^{[24]}$ observational data does not equate participants' understanding or meaning perspective.

Program directors, level or course coordinators and facilitators were interviewed during the second phase. Interviews addressed questions related to the $\mathrm{CBE}$ context in each institution. For the SANC education committee members, interview questions focused on what the policy makers meant by CBE, implementation of a CBE curriculum, competencies required from these graduates and their role as policy makers in $\mathrm{CBE}$.

\subsection{Data analysis}

Data collection and the initial stages of data analysis (category development, category saturation and concept development) were conducted simultaneously. This analytic process yielded concepts which were described in terms of their properties and dimensions. Some of the concepts emerged from the words and phrases used by informants and some were derived from the literature; which is a perfectly permissible process according to Strauss and Corbin. ${ }^{[22]}$ Open coding involved asking questions and making comparisons to ascertain similarities and differences between concepts. Similar concepts were grouped as categories and these categories were used as codes for further data analysis. Additional questions evolved out of this coding process that produced more data. This process of coding data required repeated re-examination, interpretation and comparisons of data until the stage of category saturation was reached. 
Category reduction was achieved through axial coding by linking categories according to how they fitted the characteristics of a defined category. Categories were then linked together with the intention of understanding relationships among them. Categories that shared similar characteristics were merged into higher-order categories. At this stage, logic diagrams were drawn to uncover relationships between categories, using Strauss and Corbin's ${ }^{[22]}$ paradigm of theory development (antecedent conditions, context, action/action strategies, intervening conditions and consequences) (see Figure 1).

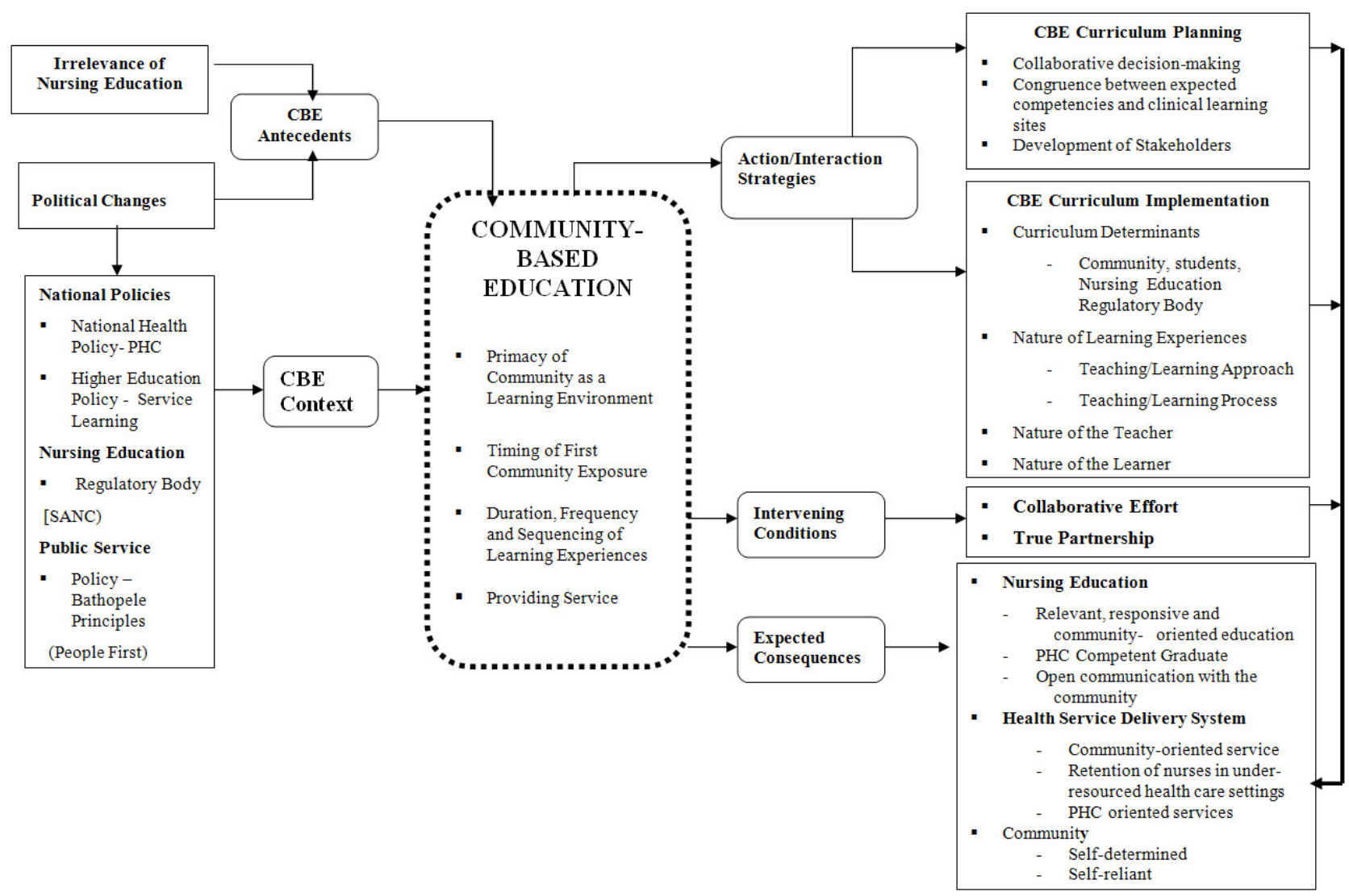

Figure 1. Schematic representation of the practice of $\mathrm{CBE}$ in basic nursing education

Selective sampling of literature followed the linking of categories to determine whether the present findings were in accordance with findings from earlier studies and existing theories. Through the process of reduction and comparison, the core category (CBE) emerged. Diverse properties began to integrate and the resulting theory began to merge. Eventually the theory solidified. More importantly, it became possible to delimit the theory with a set of higher-level concepts. The theory was finalized at this stage and was again compared with the data.

\subsection{Academic rigour}

To achieve credibility in this study, a detailed description of the research process and the process of data analysis was adhered to, as stated in Lincoln and $\mathrm{Guba}^{[25]}$ he categories discovered were discussed between the two authors at regular intervals and other experts in qualitative research were consulted. Data was triangulated by using three data collection techniques. Data was also checked by participants through focus groups, which were held in each institution at the end of phase one. To ensure dependability, data quality checks or audits, peer review of coding and consultation of qualitative research experts were conducted. Experts in qualitative research were consulted to monitor the data collection process, and the analysis and interpretation of the data. Triangulation provided the strongest measure for dependability. Confirmability was promoted by taking detailed field notes, tape recording and transcribing interviews verbatim to identify variations in responses and by making field notes available for audit checks and verification. To ensure that the developed theory was applicable to the context under study, purposive sampling was used to select only those nursing education institutions with established CBE programs. A detailed description of the whole process of the research study, 
including the research procedures and findings, is provided in order to enhance transferability to other similar contexts.

\subsection{Ethical considerations}

Ethical clearance was obtained from the university's ethics committee. Permission was sought from the heads of the schools of nursing that were selected for inclusion in the study, the Department of Health and the SANC, as policymakers. Participation was voluntary and informed consent was obtained from the participants. Gathered data was treated confidentially and code numbers were assigned to participants' taped transcripts to ensure anonymity.

\section{RESUlts}

The theory presented in this paper was built on the results obtained from open and axial coding processes which led to the emergence of CBE as the core variable (see Figure
1). The core category was systematically related to other categories as per Strauss and Corbin's paradigm. While the results are extensive and are published elsewhere, ${ }^{[4,18]}$ they have been summarised for the purpose of this article.

The results at this stage of data analysis had irrelevance of nursing education and political change in the country as antecedents of CBE. Nursing education was not responsive to the needs of the health care system and the graduates produced were not in possession of relevant competencies to address the needs of the society. The antecedents created a context that was seen as conducive to change in nursing education through development of enabling national policies, for both the health and the education systems in the country, as outlined in Table 1. These policies provided basis for reforms in nursing education and the education policies in particular facilitated the implementation of government's agenda of transforming the education system in the country.

Table 1. CBE antecedents and context

\begin{tabular}{|c|c|c|}
\hline $\begin{array}{l}\text { Elements of Strauss and } \\
\text { Corbin's Paradigm }\end{array}$ & Category/subcategories & Supporting Extracts \\
\hline \multirow{2}{*}{ CBE Antecedents } & Irrelevance of nursing education & $\begin{array}{l}\text { They (nurses) were not prepared to serve in rural and under } \\
\text { resourced communities } \\
\text { the students were prepared to serve mainly in that setting(hospital) }\end{array}$ \\
\hline & Political changes & $\begin{array}{l}\text { With the changes to a democratic government ... Nursing } \\
\text { education was challenged to contribute in making health care } \\
\text { accessible to all, by changing to CBE. }\end{array}$ \\
\hline CBE Context & Enabling national policies & $\begin{array}{l}\text { PHC is the policy from the government. Our school adopted a CBE } \\
\text { curriculum because it was a directive from the government } \\
\text { The new curriculum took into consideration a number of National } \\
\text { policies, such as PHC policy, Higher education policy on service } \\
\text { learning as well as the Bathopele (People First) principles. }\end{array}$ \\
\hline
\end{tabular}

The process of developing and implementing CBE emerged as action/interaction strategies in this study. Action and interaction strategies include activities and or strategies devised to manage, handle/carry out or respond to a phenomenon under a specific set of perceived conditions. ${ }^{[22]}$ Collaborative decision making between nursing education institutions, the health service sector and the community in planning for change, as well as the nature of the educative process were identified as essential for successful implementation of a CBE curriculum. What emerged as embedded within the educative process were the determinants of the curriculum, the nature and sequencing of community-based learning experiences, teaching approaches, teaching/learning process, the nature of the teacher, and the nature of the learner as per supporting extracts in Table 2.

The findings revealed some intervening conditions that in- fluenced the successful implementation of CBE. According to Strauss and Corbin ${ }^{[22]}$ intervening conditions represent the broader structural context pertaining to a phenomenon, and either facilitate or constrain the action or interactional strategies that are performed with a specific context. In this study these included a collaborative approach, true partnership and government involvement, as CBE implementation is heavy on resources (see Table 3). Strauss and Corbin's paradigm $^{[21,22]}$ also includes consequences or outcomes the outcome of actions and interactions, which could be intended or undesired outcomes. What emerged as expected outcomes in this study were relevant and responsive nursing education as shown in Table 3.

On completion of organising emerging categories around Strauss and Corbin's paradigm, the researcher engaged in selective coding of data. Selective coding, which is the last 
phase in Strauss and Corbin's grounded theory approach, included validating relationships between and amongst the emerging categories and establishing those categories that needed further refinement and development. ${ }^{[22]}$ A selective literature review was conducted with a view to validating emerging theoretical concepts and the researcher consulted with key informants and engaged with the data until theoreti- cal saturation of all the concepts was achieved. Relationships were noted between the concepts, which ultimately created the storyline. ${ }^{[22]}$ These concepts formed the building blocks of the middle-range theory. ${ }^{[22]}$ This paper is not aimed at explicating on the process through which the theory was developed, but rather on presenting the middle-ranged theory that emerged from this study.

Table 2. CBE action and interaction strategies

\begin{tabular}{|c|c|c|}
\hline $\begin{array}{l}\text { Elements of Strauss and } \\
\text { Corbin's Paradigm }\end{array}$ & Category /subcategories & Supporting Extracts \\
\hline \multirow{10}{*}{$\begin{array}{l}\text { Action and Interaction } \\
\text { strategies }\end{array}$} & Curriculum planning & \multirow{2}{*}{$\begin{array}{l}\text { Involving them (stakeholders) was crucial because decisions had } \\
\text { to be made concerning the priority problems to be addressed as } \\
\text { well as the competencies of the new graduate to be produced from } \\
\text { the proposed curriculum. }\end{array}$} \\
\hline & Collaborative decision-making & \\
\hline & $\begin{array}{l}\text { Congruence between expected } \\
\text { competencies and clinical } \\
\text { learning sites }\end{array}$ & $\begin{array}{l}\text { In CBE we say we want to produce graduates who will be able to } \\
\text { serve communities at all levels, more importantly those who are } \\
\text { interested in serving under-resourced communities. This should } \\
\text { then be reflected in our selection of community sites. }\end{array}$ \\
\hline & Development of stakeholders & $\begin{array}{l}\text { The coordinator from the community-partnership program } \\
\text { organized experts in CBE to prepare us for the facilitation of } \\
\text { learning in the community. }\end{array}$ \\
\hline & Curriculum implementation & \multirow{2}{*}{$\begin{array}{l}\text { The curriculum content is determined by the needs of the } \\
\text { community, the students' interests and the regulatory body. }\end{array}$} \\
\hline & Curriculum Determinants & \\
\hline & Nature of learning experiences & $\begin{array}{l}\text { Learning activities distinctive of CBE... take place in the } \\
\text { environment which is viewed as the main environment in } C B E \text {, the } \\
\text { community. }\end{array}$ \\
\hline & $\begin{array}{l}\text { Teaching and learning } \\
\text { approaches }\end{array}$ & $\begin{array}{l}\text { Experiential learning is dominating especially in } \\
\text { community-based learning activities. } \\
\text { We use a combination of strategies that promote active learning, } \\
\text { strategies such as group-based learning, experiential learning, } \\
\text { self-directed learning, and problem-based learning. }\end{array}$ \\
\hline & Nature of the teacher & $\begin{array}{l}\text { The facilitator guiding them (students) should have creative and } \\
\text { innovative ideas, be supportive, flexible and adaptable to } \\
\text { facilitate the development of the same skills in her students. }\end{array}$ \\
\hline & Nature of the learner & $\begin{array}{l}\text { The students are also regarded as sources of the curriculum } \\
\text { content. } \\
\text { The students are the ones actively engaged in the process of } \\
\text { knowledge construction. }\end{array}$ \\
\hline
\end{tabular}

\section{A MIDDLE-RANGE THEORY OF COMMU- be generated. ${ }^{[26]}$}

\section{NITY BASED NURSING EDUCATION}

Middle-range theories describe a view of reality that deals with a specific phenomenon. Middle-range theories are more concrete, narrower and more limited in scope than grand theories. However, although they are made up of a limited number of concepts and propositions at a lower level of abstraction, they have the promise to develop into a high level theory. They are empirically measurable and have a set of relational statements from which a testable hypothesis may
Embedded in Chinn and Jacob's ${ }^{[27]}$ definition of the term "theory" are six components of a theory, which include (a) goals of a theory, which are described as the general purposes for which the theory is developed and suggested boundaries to which the theory applies; (b) concepts, which are described as symbolic representations of reality, serving as building blocks of a theory; (c) definition, defining concepts to clarify their meaning in relation to the developed theory; (d) relationship statements, the statement providing linkages between 
concepts; (e) theory structure, which gives the overall form to the conceptual relationships within it; and (f) assumptions, which are basic givens, or accepted truths, that are fundamental to theoretical reasoning. Furthermore, Fawcett ${ }^{[28]}$ posits that each discipline singles out its own meta-paradigm, which is used in developing a theory in that specific discipline. This paradigm consists of specific concepts or themes around which a theory is developed. In this particular study, the framework for educational analysis presented by Tan- ner and Tanner ${ }^{[29]}$ is used to explicate the educative process, which includes: (a) nature of the curriculum; (b) nature of knowledge; (c) teaching/learning process; (d) nature of the teacher; and (e) nature of the learner.

This community-based nursing education middle range theory in the South African context is interpretive explanatory. Neumann ${ }^{[30]}$ maintained, "the purpose of interpretive explanation is to foster understanding" (p. 58) and explain why and the extent to which one concept is related to another. ${ }^{[27]}$

Table 3. CBE intervening conditions and expected consequences

\begin{tabular}{|c|c|c|}
\hline $\begin{array}{l}\text { Elements of Strauss and } \\
\text { Corbin's Paradigm }\end{array}$ & Category /subcategories & Supporting Extracts \\
\hline \multirow{3}{*}{ Intervening conditions } & Collaborative Effort & $\begin{array}{l}\text { Successful implementation and sustenance of CBE programs depends } \\
\text { on a collaborative effort between these three parties, the school, the } \\
\text { health care providers and the community. }\end{array}$ \\
\hline & True Partnership & $\begin{array}{l}\text { In order for our community-university partnership to materialize, } \\
\text { agreements were entered into by these three parties, the purpose of the } \\
\text { partnership was clarified to all, and responsibilities of all members } \\
\text { were tabled. }\end{array}$ \\
\hline & Government involvement & $\begin{array}{l}\text { The government ... should assist because running CBE programs is } \\
\text { very expensive. } \\
\text { the government ... help us at least with transport. }\end{array}$ \\
\hline \multirow{3}{*}{ Expected consequences } & Nursing Education & $\begin{array}{l}\text {... produce graduates with relevant competencies. Relevant } \\
\text { competencies in our South African context are competencies which are } \\
\text { PHC related. }\end{array}$ \\
\hline & Health Service delivery & $\begin{array}{l}\text { Health care institutions at all levels will be staffed with graduates who } \\
\text { can competently function in those areas. }\end{array}$ \\
\hline & Community & $\begin{array}{l}\text { Our program should contribute something to the community by giving } \\
\text { them information on health promotion and prevention of illness, } \\
\text { healthy life styles. }\end{array}$ \\
\hline
\end{tabular}

\subsection{Goals of the middle-range CBE theory}

The CBE theory presented in this article is aimed at providing a framework to guide the practice of CBE in basic nursing education in South Africa. As an explanatory theory, it aims to provide an explanation of $\mathrm{CBE}$ in basic nursing education in South Africa. Although the theory was developed within the South African context and within a basic nursing education program, it is broad enough to be applicable to a variety of undergraduate health professions' education programs in any developing and/or underdeveloped country. The theory could also contribute to the limited theoretical or scientific body of knowledge in CBE.

\subsection{Basic assumptions}

The middle-range community-based nursing education theory presented here is built on the assumptions that (a) education is a social instrument; (b) education is a political instrument; (c) knowledge is organized, but tentative, sub- jective, dynamic and contextualised information that has a utilitarian value at a specific time and in a specific situation; (d) learning is a natural and creative activity; and (e) skills are the basis for learning during the meaning making process. ${ }^{[31]}$

Education is a social instrument: Education as a social instrument addresses social needs and problems to bring about change in society. Central to education being a social instrument is the social relevance of education and social responsibility. Social relevance in such education is viewed in terms of education addressing the needs and problems of the particular society. The learners are socialized into being socially responsible and thus develop the knowledge, skills and attitudes they require as responsible citizens, such as appreciating diversity, valuing cultural differences, solving problems cooperatively, thinking creatively and critically, and making responsible decisions and accounting for them. This means that community-based nursing education is an instrument that brings about change. 
Education is a political instrument: Education is a powerful political instrument that can be used to bring about change in countries, health care systems and communities. As politics is associated with power, those in power fulfil their visions and missions through education, using teachers and learners as agents of change. The ultimate aim of education as a political instrument is to serve the interests of the government of the day. ${ }^{[32]}$ Although, there is possibly a high level of subliminal indoctrination in education of this nature, education as a political instrument facilitates the implementation of national policies, enhances knowledge and understanding of the workings of the political system and, in a democratic country, promotes democratic values and practices, as is the mandate from the South African government.

Knowledge is organized, but tentative, subjective, dynamic and contextualised information that has a utilitarian value at a specific time and in a specific situation: This model presents knowledge as grounded on experience, contextualised and socially constructed. Knowledge arises from the process of meaning- making, which, according to Cole, ${ }^{[31]}$ is the act of applying one's skills to the organization of information, experience and behaviour. According to this author, this act of meaning-making includes exploring, experiencing, problem-solving, and building content and knowledge from experience. Although the end product of this act is viewed as knowledge, it is tentative and likely to change with time and context.

Learning is a natural and a creative activity: The intrinsic motivation to learn makes learning natural as one has that natural inclination to engage in an investigative action, seeking meaning from the new experience, as stated in Cole. ${ }^{[32]}$ Relevance, especially personal relevance, contributes to making learning more natural, in that what is to be learned has a personal value to the individual, who therefore has a strong desire to explore. Creativity comes forth during the process of knowledge construction and meaning-making when students take an active role, with the teacher in the background facilitating and directing learning. Learning becomes a creative process as the students interact, engage in a dialogue and think through unfamiliar concepts, taking context into consideration. All members of the team actively participate, drawing from their pool of previous experience, integrating the past with the present, utilizing information from a number of disciplines and applying information from their cultural heritage to the present to create meaning. The outcome of this process is a unique product (knowledge) creatively constructed by the community of learners.

Skills are the basis for learning during the meaning making process: In the context of meaning making, skills serve as the means by which individuals construct responses and purposeful actions towards the goals of meaning making. They use skills such as problem solving, creative and critical thinking, communication skills and many other important skills. Such learning processes require learners to acquire skills in identifying resources and accessing information independently from those identified resources. The nature of the educative process is closely in line with the outcomes of education as the nature of the learning experiences and the clinical learning environment have a direct influence on the graduate produced.

\subsection{Substantive concepts and conceptual relationships}

Regarding the definition of concepts, Chinn and Jacobs ${ }^{[27]}$ stated that some theorists define words or concepts by how they are utilized within a theory (relatively associative definition), whilst others define terms specifically by what they mean (relatively specific definition). The substantive concepts of the $\mathrm{CBE}$ middle range theory presented in this article are defined in a relatively associative manner.

CBE, as the phenomenon of interest in this study, is treated as the main concept. The other major concepts are directly linked to the main concept and these include (a) relevant education; (b) responsive education; (c) education for social justice; (d) CBE as a conscious and deliberate PHC socialization process; and (e) a process-outcomes oriented education. The first four major concepts developed as characteristics of $\mathrm{CBE}$ in basic nursing education in South Africa. Processoutcomes oriented education emerged as the educational paradigm underpinning the practice of CBE (see Figure 2).

$\mathrm{CBE}$ as relevant education: $\mathrm{CBE}$ emerged as education that promotes relevance in nursing education and thus facilitates the development of graduates who will be equipped with the knowledge, skills and attitudes that are required to meet the needs of all communities and the health care system. The deliberate socialising of nursing students throughout the duration of the education program familiarises them with PHC settings, thus making it more likely that they will be willing to serve in rural and under-resourced health care settings. This would meet national and global shifts in health professions' education re-orienting its emphasis from hospital and curative care towards ensuring that graduates are equipped with knowledge and skills essential for practice in PHC driven health systems. ${ }^{[2,33,34]}$ An added advantage is that the life-long learning skills acquired through active learning within a CBE program ensures sustained capacity to continually learn and develop alongside the ever evolving health care system.

$\mathrm{CBE}$ as a conscious and deliberate PHC socialization pro- 
cess: Four common core characteristics distinguishing CBE in basic nursing education were identified. These were (a) the primacy of the community as a learning environment; (b) timing of first community exposure; (c) frequency, duration and sequencing of community based learning experiences; and (d) service provision. The last characteristic will be dealt with under the subsection "Education for social justice".

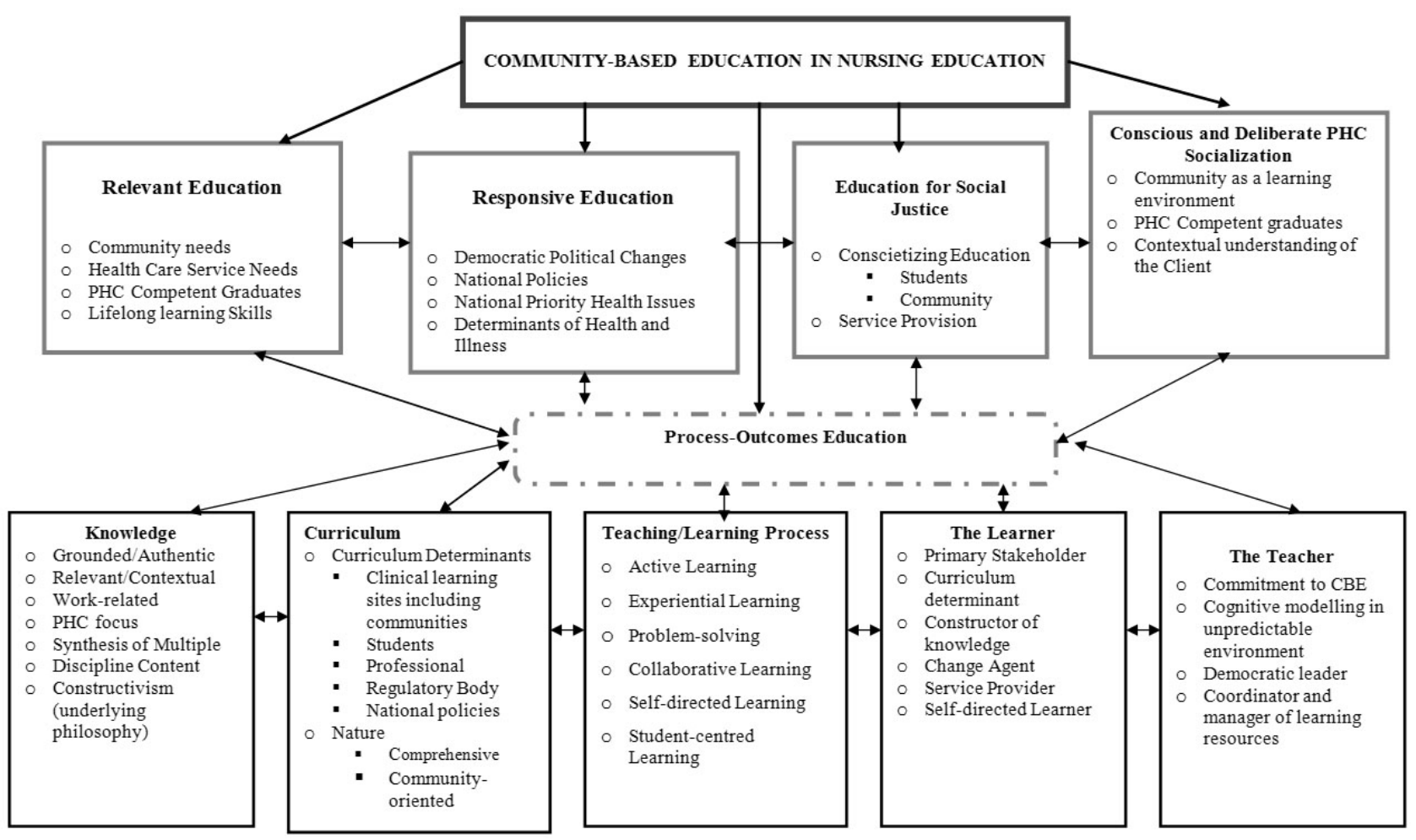

Figure 2. A conceptual model of community-based nursing education in South Africa

Firstly, students are exposed to learning experiences that are only found in community settings. The community as a primary learning environment in $\mathrm{CBE}$ creates space and opportunities for raising the students' and community's consciousness regarding the socio-political, economic and cultural issues that impact on health. This learning environment provides a holistic and contextualised view of a client, who is met in his/her natural setting. Secondly, CBE is characterised by early exposure to community settings, preferably during the first year, to ensure early socialisation of students to realities in the community and to PHC. It is believed that the students are more receptive to changes and new ideologies at this early stage in the program as they have not yet been introduced to curative focused care and are still able to identify with the community's perspective on issues. This view of CBE is in agreement with a number of authors ${ }^{[34-36]}$ views on this phenomenon. Thirdly, CBE is distinguished by the duration, frequency and sequencing of community-based learning experiences. The students in a CBE curriculum should be repeatedly exposed to community settings to familiarise them with the environment, to build and reinforce a strong PHC foundation and to develop in them an interest to practise in such settings. Sequencing of learning experiences in a CBE curriculum gives a holistic view of the client, from the healthy client in the community or primary health care settings, to secondary and tertiary health care settings.

$\mathrm{CBE}$ as responsive education: In the context of this theory, $\mathrm{CBE}$ as responsive education is education that responds to the national policies, national priority health needs and prevalent community needs. More succinctly, CBE is underpinned by the understanding that education occurs within a particular historical, political and socio-economic context and that "it is imperative teachers and learners engage in ongoing examination of the possible ways in which their students' educational futures are either constrained or enhanced by existing curricular priorities and classroom strategies ..."[36] (p. 7). Hence, it is argued that it is the nature of the educative process, that is, the nature of the curriculum, the teaching learning process, the nature of the teacher and the nature of the learner that determines the extent to which any educational program is responsive to the context in which it occurs. 
CBE as education for social justice: Treadwell and Northridge ${ }^{[36]}$ make a poignant point in stating that "when an entire community suffers from a health concern, that concern becomes a social justice issue" (p. 12). These authors further argue that in order to achieve true social justice we must call upon the "popular and political will to address the root causes of current inequities, notably poverty ... maldistribution of resources within society ..." including such forms of discrimination as the "disenfranchisement of individuals and groups"[36] (p.18). CBE as education for social justice places emphasis on immersion of learners within communities. Through engaging and serving under-resourced and rural communities, the students are exposed to social injustices which arise mainly from the issues of inequality, issues that are regarded as undeniably linked to health problems prevalent in the communities.

In Freire's ${ }^{[37]}$ language, in this type of education, the students in community settings engage in emancipatory inquiry, the goal of which is to bring about change and to help students understand oppression from the community's perspective. Oppression, in the context of this study, may be in a form of social or health problems as a result of unequal distribution or lack of resources due to social injustices. It might be lack of information on health issues, lack of knowledge of those factors (psycho-socio, political, economic, and cultural factors) contributing to health and disease in the community due to illiteracy or fear of challenging the status quo. The students have a responsibility to make the community members aware of the issues affecting their health and to assist the communities in their efforts to change the situation.

CBE therefore raises the consciousness of students to issues confronting communities; issues such as poverty, homelessness, high crime rate, malnutrition, teenage pregnancies, child abuse, drug and alcohol abuse, and many other contemporary issues which impact on health. As the students explore these issues, they become equipped to raise the consciousness of the community members to them, with the intention of influencing the community to confront these situations in order to better themselves. Interacting with affected communities and learning through providing service to these communities develops an interest in social justice and a commitment to serve such communities. Some communities, however, may choose a political social action, a solution, which might be quite different from what the CBE program planners had in mind. To this end, Jakubowski ${ }^{[38]}$ posits that "the ways in which learning comes to be linked with political social action is dependent upon the comfort level of the respective participants" (p. 26). CBE as education for social justice creates a platform for learners, the community and teachers to question issues surrounding inequities and access health with a view to transformative, rather than revolutionary action.

The preceding paragraphs illustrate the meaning of CBE in basic nursing education in South Africa. Essentially it is believed that none of the core concepts of CBE that have been presented are independent. Instead they are all linked to constitute what is practised as $\mathrm{CBE}$ in nursing education in the country. Nevertheless, as noted earlier in this paper, educational relevance, education for social justice and educational responsiveness are only possible when educational programs place emphasis on both the process and outcomes.

Education as a process and outcomes: This major concept, education as a process and outcomes, explains the nature of the educative process in CBE. In this model, CBE, as process-outcomes driven education, implies that both the process of learning and the outcomes of education are important. The sub-concepts that constitute the educative process in CBE include collaborative curriculum decision- making, grounded knowledge, active learning and skills development. The meta-paradigm for educational theorizing, that is, (a) the nature of curriculum; (b) the nature of knowledge; (c) the teaching/learning process; (d) the nature of the learner; and (e) the nature of the teacher, is used to explain the subconcepts emanating from the data on the educative process in $\mathrm{CBE}$.

The nature of the curriculum: The curriculum is a collaborative effort by all major stakeholders, the academic institution, the health care system and the community, to ensure that the developed curriculum is plausible, fit for the purpose and implementable. It is crucial that the stakeholders have an input into the priority health issues to be included in the curriculum. These views echo those of Treadwell et al., ${ }^{[36]}$ who warn that "one size does not fit all when it comes to improving access to ... health care for the underserved populations" (p. 17) and that communities must be involved in the planning and implementation of community based primary care services. This is equally true for a curriculum in a community based nursing education program.

The curriculum determinants in this theory include (a) the community; (b) the students; and (c) the nursing education regulatory body. The community has an outstanding role in a CBE curriculum that is aimed at orientating and socializing the students in understanding community needs and problems from the community's perspective. The input from the community (a) enhances the relevance of the curriculum to the priority needs of the surrounding community; (b) ensures that the curriculum content is contextualised and unique, as it is based on the needs of the surrounding community; and (c) ensures that the CBE curriculum is dynamic and is based 
on the present, because of the changes taking place in the community.

The students are also regarded as sources of the curriculum, as their needs and interests are taken into consideration, especially those relating to the desired graduate competencies, thus making the curriculum a responsive one. The interests and needs that the learners bring with them to the classroom form an emerging curriculum and the educational institution's curriculum arises from learner's experience and also develops experience in the learner. ${ }^{[36]}$

The nursing education regulatory body is another important determinant of the curriculum and ensures, through policy directives, that an enabling environment is created. According to this particular CBE theory, the nursing regulatory body works closely with the Department of Health to ensure that the priority needs of service are catered for in basic nursing education curricula.

The teaching/learning process: In CBE, the teaching/learning process is characterised mainly by active learning, selfdirected learning and collaborative learning. To reiterate, active learning in the context of this study refers to learning where students move away from being passive recipients of knowledge to being active participants. ${ }^{[39]}$ In doing most of the work themselves, they learn through experience, engaging in the process of meaning making through knowledge construction, problem-posing and problem solving learning activities, as well as in the application of what has been learned, with teachers facilitating and directing the process of learning. On a similar note, Jakubowski ${ }^{[38]}$ asserts that participatory active learning that connects the classroom and the community is the most effective strategy for engaging students in a truly transformative learning process. Through critical reflection and dialogue, teachers, learners and the community engage in the dialectical process of questioning their world and that of others, and thus begin to unravel the socio-political context of health and disease.

Collaborative learning as part of the teaching/learning process, where students learn in groups, socialises the students to their professional roles. Nurses, seldom, if ever, work alone. CBE thus provides opportunities for the development of leadership skills and facilitates an understanding of different personalities that may be encountered when working with others.

The nature of knowledge in CBE: Knowledge in this CBE theory is regarded as knowledge if it is grounded on real life experiences in a clinical learning environment and is socially constructed in communities of learning by the students under the guidance of the facilitator. Social constructivism is

Published by Sciedu Press the dominant theory when it comes to knowledge construction. Factors contributing to the development of grounded knowledge include (a) rich authentic environments, such as community settings; (b) communities of learning, as students learn in teams or small groups; and (c) authentic learning activities, which are real learning activities taking place in real life communities. Focus is on facilitating the development of work-related knowledge through engaging on activities such as health screening, health education, immunisation programs, growth monitoring programs, nutrition programs and many other work related activities.

The nature of the learner: The learner in this theory is characterised by being a source for the $\mathrm{CBE}$ curriculum, contributor to knowledge, service provider, change agent and a self-directed learner. The learners in this theory are regarded as primary stakeholders as all $\mathrm{CBE}$ activities revolve around them. The program aims at ensuring that the type of education provided to students is relevant and responsive, prepares them for issues of social injustice and gives them a solid PHC foundation. Learners are expected to be actively involved in learning and to be self-directed. Emphasis is placed on inquiry, critical analysis and self-evaluation.

The nature of the teacher: The nature of the learning environment (community) used for teaching/learning purposes in this theory requires a teacher with a commitment to CBE because of the unfamiliarity of the learning environment as well as changes in the responsibilities of the teacher as a result of using this learning setting. The teacher is characterised by cognitive modelling in an unpredictable learning environment, where learning depends on what emerges as a learning experience at that particular time. The teacher is therefore expected be innovative, creative and inquisitive, a fast and critical thinker and someone who can come up with alternative solutions when the need arises. The nature of the learner and the nature of the educative process require the teacher to demonstrate democratic leadership in managing the learning environment. Rather than actively teaching, this teacher encourages learners to learn actively and take a leading role in the teaching/learning process. Rather than providing knowledge, this teacher facilitates the process of knowledge construction, serving as a resource person, not a giver of information.

\section{CONCLUSION AND RECOMMENDATIONS}

Attempts were made to ensure that the developed theory met Strauss and Corbin's ${ }^{[22]}$ four central criteria for a good theory (fit, understanding, generality, and control). According to Strauss and Corbin, ${ }^{[22]}$ the theory should (a) fit the area of study, provided it has been carefully derived from diverse data and is faithful to the everyday reality of the area; (b) 
provide understanding, and be comprehensible to both the persons studied and others involved in the area; (c) provide generality, given that the data is comprehensive, the interpretation conceptual and broad, the theory includes extensive variation, and is abstract enough to be applicable to a wide variety of contexts in the area; and (d) provide control, in the sense of stating the conditions under which the theory applies and provides a basis for action in the area. It is hoped that the middle-range CBE theory presented in this article meets these criteria. Nevertheless, this tentative, newly developed theory requires that it be subjected to scholarly critique and validity testing in order to facilitate its evolvement towards becoming a higher level substantive theory. In addition, the test of the validity of any theoretical propositions lies not only on the comprehensiveness of its processes, but also on the extent to which the espoused educational outcomes are met. A study examining the impact of CBE on graduates' practice would strengthen the plausibility of the hypothetical statements made in this report.

\section{Limitations}

Obtaining relevant empirical literature on CBE was a challenge. Most of the literature provided only descriptions of existing CBE programs and other articles were position papers on $\mathrm{CBE}$.

Inclusion of the impact of CBE on graduates' practice would have strengthened the validity of the theoretical propositions made in this study. Nevertheless, it is believed that the detailed description of the research process, strategies used to ensure academic rigour and the information appearing in Figure 1 should compensate for this particular limitation.

\section{Conflicts of Interest Disclosure}

The authors declare that there is no conflict of interest statement.

\section{REFERENCES}

[1] World Health Organisation. The World Health Report: Primary Health Care - Now more than ever. Geneva: Switzerland. 2008.

[2] World Health Organisation. Transforming and scaling up health professionals' education and training: WHO Guidelines. Geneva: Switzerland. 2013.

[3] Nokes KM, Nickitas DM, Keida R, et al. Does Service-Learning Increase Curtural Competency, Critical Thinking and Civic Engagement. Journal of Nursing Education. 2005; 44: 65-70. PMid:15719713

[4] Mtshali NG. Implementing Community-Based Education in basic nursing education programs in South Africa. Curationis. 2009; 32(1): 25-32. http://dx.doi.org/10.4102/curationis.v3 2 i 1.870

[5] Frenk J, Chen L, Bhutta ZA, et al. Health professionals for a new century: transforming education to strengthen health systems in an interdependent world. The Lancet. 2010; 376(9756): 1923-1958. http://dx.doi.org/10.1016/S0140-6736(10)61854-5

[6] Touré B, Avocksouma DA, Nyoni J, et al. Road map for scaling up human resources for health improved service delivery in the African Region 2012-2013. The African Health Monitor. 2013.

[7] World Health Organisation. WHA 64.7 Strengthening nursing and midwifery. Geneva: Switzerland. 2011.

[8] Department of Education. White Paper on A Programme for Transformation in Higher Education. Government Gazette, 17910. Pretoria 1997.

[9] Department of Health. White paper on the transformation of health care system in South Africa. Government Gazette, 382, 17910. Pretoria. 1997.

[10] South African Nursing Council, Education and training of South African nurses: transforming nursing education. Unpublished Manuscript. Pretoria, South Africa. 1999.

[11] Diab P, Flack P. Benefits of community-based education to the community in South African health science facilities. Afr J Prm Health Care Fam Med. 2013; 5(1).
[12] Baglin MR, Rugg S. Student nurses' experiences of communitybased practice placement learning: A qualitative exploration. Nurse Education in Practice. 2010; 10: 144-152. PMid:19570716 http: //dx.doi.org/10.1016/j.nepr.2009.05.008

[13] Kaye DK, Muhwezi WW, Kasozi AN, et al. Lesson learnt from comprehensive evaluation of community based education in Uganda: a proposal for an ideal model community based education from health profession training institutions. BMC Medical Education. 2011; 11: 1-9. PMid:21362181 http://dx.doi.org/10.1186/1472-692 $0-11-7$

[14] Farsi Z, Dehghan-Nayerie, N, Negarandeh R, et al. Nursing profession in Iran: An overview of opportunities and challenges. Japan Journal of Nursing Science. 2010; 7: 9-18. PMid:20618672 http: //dx.doi.org/10.1111/j.1742-7924.2010.00137.x

[15] Foli KJ, Braswell M, Kirkpatrick J, et al. Development of Leadership Behaviors in Undergraduate Nursing Students: A ServiceLearning Approach. Nursing Education Perspectives. 2014; 35(2): 76-82. http://dx.doi.org/10.5480/11-578.1

[16] Okayama M, Kaji E. Does community-based education increase students' motivation to practice community health care? a cross sectional study. BMC Medical Education. 2011; 11: 19. PMid:21569332 http://dx.doi.org/10.1186/1472-6920-11-19

[17] Macnab A, Kasangaki A, Gagnon F. Health Promoting Schools Provide Community-Based Learning Opportunities Conducive to $\mathrm{Ca}$ reers in Rural Practice. International Journal of Family Medicine. 2011. PMid:22295197 http://dx.doi.org/10.1155/2011/89 2518

[18] Mtshali NG. Conceptualization of community-based education in basic nursing education in South Africa: a grounded theory analysis. Curationis. 2005; 28(2): 5-12. http://dx.doi.org/10.4102/c urationis.v28i2.939

[19] Tanner CA. Transforming Pre-licensure Nursing Education: Preparing the New Nurse to Meet Emerging Health Care Needs. Nursing Education Perspectives. 2010; 31(6): 347-353. PMid:21280438 
[20] Ildarabadi E, Karimi H, Heydari A, et al. The process of community health nursing clinical clerkship: A grounded theory. Iranian Journal of Nursing and Midwifery Research. 2013; 18(6): 457-467. PMid:24554943

[21] Strauss A, Corbin J. Basics of Qualitative Research. Techniques and Procedures for Developing Grounded Theory (3rd Ed). Sage, Newbury Park CA; 2008.

[22] Strauss A, Corbin J. Basic qualitative research: grounded theory procedures and techniques. Sage, Newbury Park CA; 1990.

[23] Kendall J. Axial coding and the grounded theory controversy. Western Journal of Nursing Research. 1999; 21(6): 743-757. http: //dx.doi.org/10.1177/01939459922044162

[24] Glaser BG. Emergence vs. forcing: basics of grounded theory analysis. Mill Valley, CA: Sociological Press. 1992.

[25] Lincoln Y, Guba E. Naturalistic inquiry. Beverly Hills: Sage; 1985.

[26] Fawcett J. Criteria for evaluation of theory. Nursing Science Quarterly. 2005; 18(2): 131-135. PMid:15802745 http://dx.doi.org $/ 10.1177 / 0894318405274823$

[27] Chinn PL, Jacobs MK. Theory and Nursing: a systematic approach (2nd ed.). C.V. Mosby, St Louis MO. 1987.

[28] Fawcett, J. Analysis and evaluation of conceptual theories of nursing. F.A. Davis Company, Philadelphia. 1984.

[29] Tanner D, Tanner LN. Curriculum development: Theory into practice. (4th ed.). Macmillan, New York. 2007.

[30] Neumann WL. Social research methods: qualitative and quantitative approaches. Allyn and Bacon, London. 2000.
[31] Cole HP. Process education: the new direction for elementary secondary schools. Educational Technology Publications, Englewood Cliffs, New Jersey. 1976.

[32] Freire P. Pedagogy of Indignation. Boulder: Colorado, Paradigm. 2004.

[33] Calleson LM, Seifer SD. Institutional collaboration and competition in community-based education. Journal of Interprofessional Care. 2004; 18(1): 63-74. PMid:14668103 http://dx.doi.org/10.10 $80 / 13561820310001608230$

[34] Magzoub M EMA, Schmidt HG. Causal modelling of communitybased education. Academic Medicine. 1998; 73. 797-802. PMid:9679471 http://dx.doi.org/10.1097/00001888-199 807000-00021

[35] Tippets E, Westpheling K. The health promotion -disease prevention project: effect on medical student attitudes towards practice in medically under-served areas. Family Medicine. 1996; 28, (7): 467-471. PMid:8818615

[36] Treadwell HM, Northridge ME. Oral health is the measure of a just society. Journal of Health Care for the Poor and Underserved. 2007; 18: $12-20$.

[37] Freire P. Pedagogy of the oppressed. Penguin, Middlesex, UK. 1972. PMid:17337792 http://dx.doi.org/10.1353/hpu. 200 7.0021

[38] Jakubowski LM. Beyond book learning: cultivating the pedagogy of experience through field trips. The Journal of Experiential Learning. 2003; 26(1): 24-33. http://dx.doi.org/10.1177/105382590 302600105

[39] Ornstein AC, Levine DU. Foundations of education. New Jersey: Houghton Mifflin Company; 1997. 